\title{
THE SIGNIFICANCE OF HOWELL-JOLLY BODIES IN RED CELL PRECURSORS
}

\author{
BY \\ H. E. HUTCHISON AND M. A. FERGUSON-SMITH \\ From the Department of Haematology, the University and Western Infirmary, Glasgow
}

(RECEIVED For PUblication May 4, 1959)

During the routine examination of sternal marrow smears it was observed that the presence of nuclear fragments in red cell precursors, commonly known as Howell-Jolly bodies, was usually associated with clear evidence of vitamin $B_{12}$ or folic acid deficiency. Moreover, this seemed to be so even when the megaloblastic transformation of erythropoiesis was not well developed. With further experience the presence of Howell-Jolly bodies does appear to be a finding of diagnostic value even in doubtful cases. In order to test the validity of this impression a series of sternal marrow films examined for HowellJolly bodies has been reviewed. In this the incidence in iron deficiency and other states where $B_{12}$ or folic acid deficiency could clearly be excluded has been compared with the incidence in conditions known to be associated with $B_{12}$ or folic acid deficiency. The results of this investigation are presented here.

\section{Recognition of Howell-Jolly Bodies}

In Leishman-stained marrow smears the typical morphology is shown in the illustration. When multiple bodies of substantial size were present their appearance was unmistakable and there was no difficulty in interpretation. When, however, the structures were single and very small it was difficult to know whether they might not be an artefact of some sort or perhaps Pappenheimer bodies (see later). Since the structures were never numerous it was not possible to employ the Feulgen and Prussian blue reactions as aids to positive identification in such cases.

\section{Iron-deficiency Anaemia}

Fifty cases were collected from which sternal marrow had been obtained and the anaemia had been conclusively shown to be the result of iron deficiency by peripheral blood findings, absence of stainable iron in the marrow sections (Hutchison, 1953), and response to iron therapy alone. In only one case could infrequent erythroblasts with
Howell-Jolly bodies be found. This patient was in a poor nutritional state and had ulcerative colitis. In three other smears occasional tiny granules of doubtful nature were found, apparently in erythroblasts.

\section{Pernicious Anaemia}

Howell-Jolly bodies were readily identified in a varying proportion of megaloblasts in each of 52 consecutive cases of untreated classical Addisonian anaemia. They could be found during the preliminary scanning of the marrow smear within a period of two or three minutes in all but a very few instances. The number of megaloblasts containing these bodies seemed to be directly proportional to the degree of megaloblastic transformation and the severity of the anaemia.

\section{Other Macrocytic Anaemias}

As in pernicious anaemia, Howell-Jolly bodies were found constantly in association with megaloblastic erythropoiesis. Thus positive findings were obtained in seven patients with the malabsorption syndrome, two post-gastrectomy macrocytic anaemias, four cases of megaloblastic anaemia of pregnancy, six examples of incompletely investigated macrocytic anaemia in which the fundamental abnormality was not demonstrated, and in two cases of macrocytic anaemia after treatment with the anticonvulsant drug mysoline. Howell-Jolly bodies were also observed in two cases of severe haemolytic anaemia, and in a case of portal hypertension; once again erythropoiesis showed other evidence of megaloblastic transformation in all three cases.

\section{Miscellaneous Anaemias}

Forty marrows were reviewed for Howell-Jolly bodies. These were all cases in which stainable iron was present and there was nothing in the report on the marrow cytology to indicate that megaloblastic transformation had been suspected. 


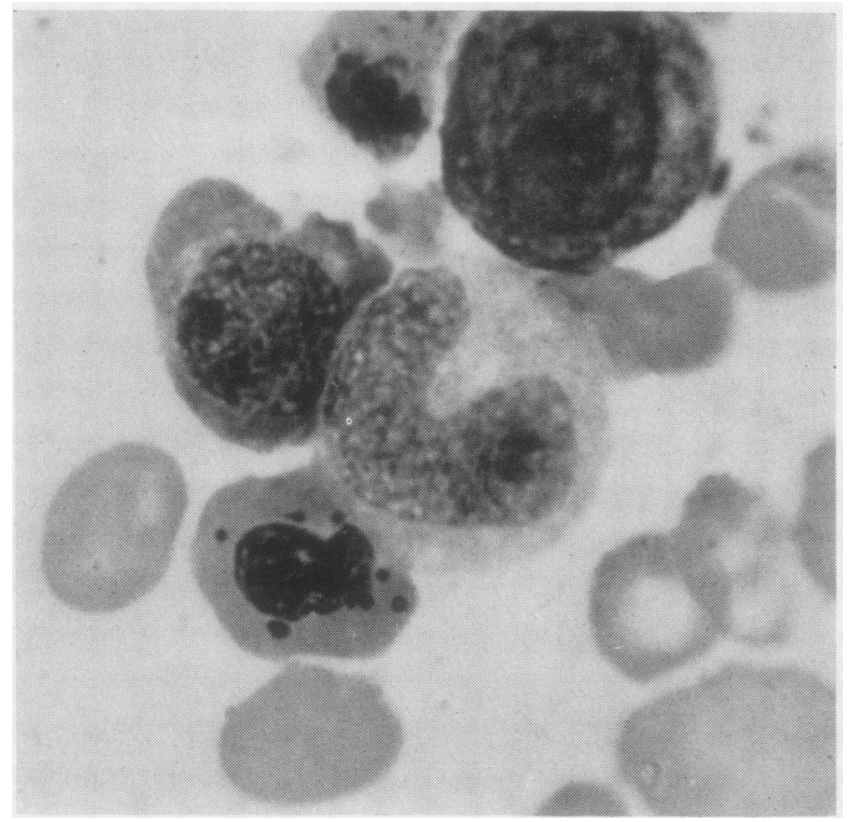

deficiency states. Many of the erythrocytes containing these single bodies were siderocytes (Pappenheimer bodies) and this was confirmed by positive iron and negative Feulgen reactions in two of the cases.

\section{Comment}

The presence of Howell-Jolly bodies in the erythroblasts has been found to $\vec{\circ}$ be a useful aid in the routine interpreta- $\vec{\partial}$ tion of sternal marrow smears. Where $\omega$ megaloblastic transformation is not well developed the finding of Howell-Jolly ? bodies provides helpful confirmatory $\vec{N}$ evidence of the tendency and suggests the ir need for further investigation along those of lines, e.g., in Addisonian anaemia presenting with neurological changes or glossitis and minimal haematological $\vec{D}$ involvement. In such cases their presence encourages further investigation by $B_{12}$ assay, the Schilling test, or folic acid clearance.

It has not been our purpose to describe

Many of these were not from primary disorders of the haemopoietic system and covered a wide variety of diseases. In 32 instances no HowellJolly bodies could be found ; four were classified as doubtful where solitary small granules, possibly artefacts, were seen, and four were found to show infrequent granules morphologically indistinguishable from Howell-Jolly bodies. The case histories and course of these eight patients were reviewed. No clear lead was obtained in the first group of four doubtful positives, whereas in the second group of four the records proved most interesting. One was finally considered to have had a spontaneous partial remission of Addisonian anaemia; another was found to have had megaloblastic anaemia during pregnancy months previously; the third was being treated for a resistant urinary tract infection when a "normocytic" anaemia was discovered. The haemoglobin rose from 60 to $75 \%$ in 14 days on folic acid. The last patient is still under investigation.

\section{Relationship to Splenectomy}

After splenectomy in four cases of haemolytic anaemia and in two cases of splenic anaemia (Banti's syndrome) single bodies similar to Howell-Jolly bodies were seen in the erythrocytes, but no typical nuclear remnants could be identified in the red cell precursors in two cases in which marrow was available. This is in sharp contrast with their distribution in $B_{12}$ or folic acid the appearance of Howell-Jolly bodies in the peripheral blood, although most of the reportef work on these structures deals largely with this aspect. Thus most textbooks contain references to the invariable finding of Howell-Jolly bodies in a proportion of the erythrocytes after splenectomy (Pepper and Austin, 1943 ; Dacie, 1954 ; Wintrobe, 1956 ; Whitby and Britton, 1957), in cases of splenic atrophy (Shur, 1908, and Schilling, 1924, see Boveri; Hirschfeld and Dünner, 1933; Boveri, 1942; Leitner, 1949), and in congenital absence of the spleen (Bush and Ainger, 1955; Wintrobe, 1956). These bodies are also said to occur frequently in severe secondary anaemia (Pepper and Austin, 1943; Whitby and Britton, 1957), in haemolytic anaemia (Pepper and Austin, 1943; Whitby and Britton, 1957), in thalassaemia (Whitby and Britton, 1957), and in leukaemia (Pepper and Austin, 1943; Whitby and Britton, 1957), as well as in pernicious anaemia (Morris, 1907) and sprue (Boveri, 1942), N but no studies of the conditions of their occurrence in red-cell precursors appears to have been made. O It is interesting to note the frequency of an $\omega$ associated megaloblastic anaemia in the case notes recorded by some investigators (see, for 0 example, Boveri, 1942), and the confusion which $\Phi$ often exists in the differentiation of Pappenheimer $\stackrel{?}{+}$ and Howell-Jolly bodies (Pepper and Austin, 1943). It is even doubtful if the structures described originally by Howell in 1890 are 
identical with what are now commonly accepted as Howell-Jolly bodies.

With regard to the origin of these bodies, it is likely that they are produced by abnormal mitosis in the late megaloblasts when single chromosomes or groups of chromosomes become detached, fail to take part in the formation of the interphase nucleus, and remain free in the cytoplasm as nuclear remnants.

It seems probable that disordered nucleic acid synthesis resulting from $B_{12}$ or folic acid deficiency is the fundamental factor in the production of this abnormal behaviour at mitosis.

\section{REFERENCES}

Boveri, R. M. (1942). Guy's Hosp. Rep., 91, 81.

Bush, J. A., and Ainger, L. E. (1955). Pediatrics, 15, 93.

Dacie, J. V. (1954). The Haemolytic Anaemias, p. 78. Churchill, London.

Hirschfeld, H., and Dünner, L. (1933). Z. klin. Med., 125, 536.

Hutchison, H. E. (1953). Blood, 8, 236.

Leitner, S. J. (1949). Bone Marrow Biopsy, p. 87. Trans. by C. J. C. Britton and E. Neumark. Churchill, London.

Morris, R. S. (1907). Johns Hopk. Hosp. Bull., 18, 198.

Pepper, O. H. P., and Austin, J. H. (1943). J. Amer. med. Ass., 122, 870.

Whitby, L. E. H., and Britton, C. J. C. (1957). Disorders of the Blood, 8th ed., p. 44. Churchill, London.

Wintrobe, M. M. (1956). Clinical Hematology, 4th ed., pp. 10521053. Henry Kimpton, London. 